\title{
MIDAS
}

Museus e estudos interdisciplinares

$7 \mid 2016$

Varia

\section{O Museu Portuense, um projecto pedagógico}

The Museu Portuense, a pedagogical project

\section{Emília Ferreira}

\section{OpenEdition}

Journals

Edição electrónica

URL: http://journals.openedition.org/midas/1114

DOI: $10.4000 /$ midas. 1114

ISSN: 2182-9543

\section{Editora:}

Alice Semedo, Paulo Simões Rodrigues, Pedro Casaleiro, Raquel Henriques da Silva, Ana Carvalho

\section{Refêrencia eletrónica}

Emília Ferreira, «O Museu Portuense, um projecto pedagógico », MIDAS [Online], 7 | 2016, posto online no dia 29 novembro 2016, consultado no dia 06 maio 2019. URL : http://journals.openedition.org/ midas/1114; DOI : 10.4000/midas. 1114

Este documento foi criado de forma automática no dia 6 Maio 2019

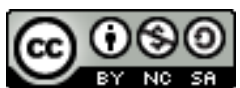

Midas is licensed under a Creative Commons Attribution-NonCommercial-ShareAlike 3.0 International License 


\section{O Museu Portuense, um projecto pedagógico ${ }^{1}$}

The Museu Portuense, a pedagogical project

\section{Emília Ferreira}

\section{NOTA DO EDITOR}

Artigo recebido a 31.03.2015

Aprovado para publicação a 02.12.2015

\section{Introdução}

1 A escolha da cidade do Porto para sede do primeiro museu público de $\operatorname{arte}^{2}$, a estabelecer em Portugal, obedece - do ponto de vista do seu fundador - a dois critérios. Um notoriamente político; o outro oportunamente baseado nas condições objectivas das colecções, particulares e eclesiásticas, artísticas, da cidade e arredores. No primeiro caso, o reconhecimento pelo apoio recebido à sua causa levou D. Pedro IV a procurar instituir um estabelecimento de utilidade pública, afirmação de glória e dignidade da nova ordem estabelecida ${ }^{3}$. No segundo, importa relembrar que a influência britânica, nutrida pelos interesses da colónia no comércio do vinho do Porto, passara para a Invicta a apetência coleccionista. Como notaria Raczynski $(1846,390)$, havia na cidade diversas famílias em cujas casas figuravam apreciáveis colecções de arte ${ }^{4}$, pelo que a cidade reunia boas condições para que nela fossem encontrados, entre os espólios das casas abandonadas pelos apoiantes da causa absolutista, peças de significativa qualidade.

2 A história, iniciada em pleno cerco do Porto, parece ter sido impulsionada por um artista da cidade, o pintor João Baptista Ribeiro (1790-1868) 5 . Lente de desenho na Academia de Marinha e Comércio do Porto, ele fora convidado para realizar um retrato do regente. Aproveitara então a oportunidade para entregar a D. Pedro uma preciosa sugestão: «Na 
occasião em que fazia o dito retrato entreguei ao Imperador hua memoria que tinha feito, mostrando a necessidade de crear no Porto hum Museo de Pinturas e Estampas e outros objectos de Bellas-Artes» (Vitorino 1930, 27).

3 A sugestão terá surtido efeito, já que a 28 de Outubro de 1832, Baptista Ribeiro recebia um ofício assinado pelo dramaturgo, poeta, jornalista e político liberal Almeida Garrett (1799-1854), então Secretário de Estado dos Negócios do Reino, pedindo-lhe que comparecesse no palácio, no dia seguinte, a fim de dar conta ao príncipe regente do estado da referida escola e da instrução pública na mesma cidade. O encontro foi proveitoso e a 11 de Abril de 1833, escrevia-se um novo capítulo desta história. Chegava ao Lente uma portaria do Ministério do Reino (Ribeiro 1836, 13), confirmando que Sua Majestade Imperial tinha a intenção de estabelecer, na cidade, um museu de pinturas e estampas, e ordenando-lhe que «examinasse quanto antes tudo o que existisse n'aquelle genero, assim nos Conventos abandonados, como nas casas sequestradas» (Ribeiro 1836, 5) 6 .

4 Estava lançado o repto e iniciado o projecto. Para o seu organizador e primeiro director, era a possibilidade de concretização de um velho sonho pedagógico.

\section{Um projecto ambicioso}

5 Baptista Ribeiro não perdeu tempo. Além da ambiciosa tarefa de organizador de espólios, trabalhou desde o início numa proposta de regulamento que, a 11 de Junho, fez chegar ao regente. Nela transparece, desde as primeiras linhas, uma clara vocação pedagógica.

6 Apontando a importância da criação museal, que afirmava sem precedentes no país, e introduzindo uma mescla de velhas esperanças (a dignificação social e cultural do artista) e outras mais conformes ao espírito do tempo, como a da instrução pública através do museu, esperava que dele florescesse a ilustração do maior número possível de cidadãos. E assim, organizado em 13 artigos, o regulamento cobria temas desde a exposição ao acesso do público e à formação de artistas.

7 Sugeria-se, desde logo, a devida colocação dos objectos (painéis, estampas, livros de arte e todas as restantes peças, nisto demonstrando já preocupações de conservação das mesmas, bem como as normas expositivas) para o seu estudo, análise e cópia (Ribeiro 1836, 16).

8 Determinavam-se igualmente as condições de acesso ao museu que deveriam ser possíveis mediante um bilhete válido por um ano (de 1 de Outubro a 30 de Junho), com a excepção dos mesmos feriados respeitados nas Academias ${ }^{7}$ e ainda o de 12 de Outubro, aniversário do fundador (Ribeiro 1836,17)8. Apesar da ambição do museu de servir o maior número possível de cidadãos, haveria condicionantes à entrada, não devendo ser franqueada a qualquer um, impedindo que os ociosos prejudicassem o trabalho dos estudiosos (Ribeiro 1836, 16), franqueando a entrada apenas a quem quisesse estudar ou instruir-se.

9 Assim se estabelecem claramente dois objectivos: o ensino dos artistas e a ilustração do povo. Aliás, o aspecto de ilustração "popular" ficava sublinhado pela possibilidade de o director:

[...] guiar os estudos em qualquer genero de trabalho, sem com tudo tomar o caracter de Mestre, mas d'amigo d'Artes, tendo sempre em vista o augmento da instrucção pública, não só deixando desenvolver livremente a índole, caracter, e genio dos estudiosos, mas até evitando systematicamente o estillo escolar ou 
amaneirado, sempre nocivo á originalidade, que tamanho valor tem na republica das Artes. (Ribeiro 1836, 16)

10 Ficava também salvaguardada a imagem do Museu como lugar de ensino livre dos cânones e das imposições dos mestres académicos. O estudo e a comparação das diversas escolas presentes no Museu $^{9}$, além da leitura dos velhos mestres, concorreriam também para a formação de artistas capazes de dar crédito ao país através da criação de obras valorosas, apoiadas num firme estudo do modelo vivo, concretamente do nu, aqui enaltecendo semelhante trabalho de aproximação e conhecimento da verdade que tantos obstáculos tivera no caminho dos artistas nacionais ${ }^{10}$.

11 Os modelos disponíveis para os artistas compreenderiam ainda as demais peças expostas, desde armas, esculturas, a alfaias e têxteis, de modo a poder contribuir para a criação dos quadros de História, visando a utilidade pública. Para facilitar o trabalho, o Museu facultaria aos estudiosos todo o material necessário (papel, lápis, pincéis, cavaletes, tintas, telas, etc.), numa proposta que seguia o modelo praticado «em Genebra e em outras cidades que possuem estabelecimentos idênticos» (Ribeiro 1836, 17) e pela qual antevemos o nível de informação do organizador ${ }^{11}$.

12 O modelo escolar transparecia igualmente noutros aspectos do regulamento. Por exemplo, de modo a que as obras de arte produzidas no espaço museal tivessem depois uso público e apropriado julgamento, dever-se-ia realizar uma exposição bienal, na qual não apenas se exporiam trabalhos de desenho, pintura, escultura, litografia e desenhos de arquitectura civil, como também escritos sobre Belas-Artes - uma novidade.

13 Essas obras obedeceriam, contudo, a escrutínio. Um júri, composto pelo director e por quatro artistas (e aprovado governamentalmente), agraciaria dois artistas com o mesmo número de medalhas de oiro de 15000 reis de peso (Ribeiro 1836,17). No respeito do amor pátrio, transmitindo os assuntos portugueses, recompensavam-se também, respectivamente com um prémio de 200000 e dois de 100000 reis, os artistas que melhor e mais originais obras apresentassem. Estas podiam mesmo ser adquiridas para futura exposição no Museu, criando, mais que um esboço de mercado de arte, uma forma de compensação à pátria pelos esforços por ela despendidos através do Museu. Além disso, contribuiriam para o desejado aumento do espólio da instituição. Assim, o campo das aquisições seria coberto por um fundo que providenciaria um enriquecimento progressivo das colecções de pintura, escultura, gravura e litografia, com a representação das melhores escolas ${ }^{12}$.

14 A actividade divulgadora do Museu estender-se-ia ainda aos artistas contemporâneos interessados ${ }^{13}$. Por um tempo nunca superior a três meses, poderiam aí expor os seus trabalhos - com a única ressalva de estes não ofenderem a moral pública. É também a primeira aproximação à tipologia dos museus dos artistas vivos, que não voltaria, tão cedo, a ter equivalente em Portugal, já que o futuro museu de Lisboa (o Museu Nacional de Bellas Artes e Archeologia), inaugurado apenas em 1884, não contemplaria esse tipo de trabalhos.

15 No que diz respeito à equipa, estava também previsto um muito reduzido quadro de pessoal. Com efeito, todo o trabalho, de clara dedicação cívica, a levar a cabo pelo Museu Portuense estaria dividido por três pessoas: o director, artista de mérito reconhecido, cuja gratidão pelo cargo deveria ser penhorada através da oferta de obra de criação própria, de modo a enriquecer o espólio da instituição, com temas e exemplos da arte clássica 
nacional; um ajudante, também artista, que manteria ainda o espaço limpo e velaria pela conservação dos objectos; e um porteiro.

\section{Instalação}

16 É tempo agora de regressar à formação do acervo original do Museu e à sua instalação, algo que iria, de diversos modos, contrariar as expectativas de Baptista Ribeiro.

17 É certo que as diligências mantiveram bom ritmo. A 6 de Julho de 1833, a Companhia do Alto Douro enviava um ofício a Baptista Ribeiro, convidando-o a escolher local na Academia ${ }^{14}$ onde as obras a recolher pudessem provisoriamente ficar. A 19 de Julho, nova portaria, orientava Baptista Ribeiro a que tratasse da instalação das peças (Ribeiro 1836, 20) e confirmava a pretensão do Lente quanto ao local: a Sala da Aula do Desenho. A 30 de Agosto, o Ministro Cândido José Xavier informava-o de que a comissão dos conventos tinha ordem de que os painéis de interesse para o futuro Museu fossem entregues, com brevidade, na mesma aula de desenho (Ribeiro 1836, 19).

18 A 10 de Setembro, o Regente sugeria a Baptista Ribeiro que escolhesse, entre os edifícios tomados aos rebeldes ausentes e sequestrados, um local para o estabelecimento. A 24 de Setembro, chegavam às mãos do Lente os quadros e as estampas (Ribeiro 1836, 19). Entretanto, um primeiro escolho surgia ao caminho, com a aprovação do laicizado Convento de Santo António da Cidade ${ }^{15}$ para instalação do Museu. Com efeito, se parecia estar em marcha o início de uma história de sucesso, na recolha, salvaguarda e conservação do património móvel, infortúnios vários espreitariam ainda o seu caminho.

Na verdade, a opção pela arquitectura conventual (tal como já acontecera em França) colmatando a inexistência de palácios condignos para os fins museais e a falta de dinheiro para os construir de raiz, tornava-se óbvia, pela dimensão dos espaços. Usava-se o pouco que havia, nas condições possíveis.

O médico, historiador, crítico de arte e museólogo portuense Pedro Vitorino (1882-1944), naquela que seria a primeira tentativa de estabelecer uma história dos museus do Porto, dada à estampa em 1930, faria uma importante reflexão sobre o tema, quase 100 anos depois. Embora reconhecendo as necessidades que obrigavam à aceitação do local para instalação do estabelecimento, deixaria uma nota crítica:

Para o projecto do museu foi dada a preferência ao convento de Santo António da Cidade, no campo de S. Lázaro, de todos talvez o menos pretendido pelas esferas políticas em vista da sua situação pouco central. Fácil foi a obtenção da casa. 0 recheio também com facilidade viria. Tudo isso dependeu das razões do momento. D. Pedro apenas as soube aproveitar. (Vitorino 1930, xiii)

E prosseguia, notando:

[A] escolha do antigo e húmido refeitório dos Capuchos, ao rés-do-chão, nada teve de feliz. Depõe mesmo em desabono dos seus organizadores. Êsse lugar era impróprio para recolher pinturas. Espaço acanhado e péssima luz. Mas talvez uma razão forte a determinasse: a simples oportunidade de conseguir uma casa, donde depois se passasse para alojamento melhor. A princípio foram concedidas várias dependências ao Museu, uma delas no pavimento superior. Mas a vizinhança de outros estabelecimentos, numerosos moradores para uma casa pequena, encurralou-o no refeitório para nunca mais. (Vitorino 1930, xv)

As críticas continuavam: 
Não muito tempo depois, o organizador abandonava a obra. Sendo conselheiro da coroa, julgou-se dispensado de mais conselhos acêrca do Museu. Seria depois com a Academia de Belas Artes.../Tudo me leva a creer que João Baptista contava com algumas salas de cima, mas as manigâncias políticas e as influências mercantis dos homens do mando, incluindo três estabelecimentos num só prédio, malograram essa esperança. (Ribeiro 1836, xv-xvi)

Entre esses outros estabelecimentos contava-se a Biblioteca Municipal do Porto, instalada no primeiro andar do convento, obrigando o Museu ao rés-do-chão, ao mencionado refeitório. Tal coabitação colocava também as questões do acesso. Um documento de 9 de Novembro de 1835, de João Baptista Ribeiro, justificava o porquê de não se abrir o claustro, onde se demoravam as estantes dirigidas à biblioteca, à passagem do público, com a precária segurança da porta do Museu e a consequente possibilidade de assalto (Vitorino 1930, 34-45).

24 A incapacidade de o edifício recolher benignamente um espólio com necessidades específicas de conservação, a que, além do mais, se pretendia emprestar gravidade cultural, foi um obstáculo a minimizar através de obras de adaptação, que correram entre 21 de Maio de 1834 e 27 de Setembro do mesmo ano, (numa base de trabalho diário «feitas a jornal» (Ribeiro 1836, 8), ao cabo das quais se lograria uma galeria de 324 palmos de comprimento (pontuada por 19 janelas, testemunho directo da arquitectura conventual, com a sua marcação de celas), 27 de largura e 23 de altura. Ao lado, um gabinete de 24 por 27 palmos e, em cima, uma sala - destinada a estudo e a exposições públicas - com 125 palmos de comprimento, 32 de largura e 25 de altura, com

[...] luz vertical, obliqua, e quasi horisontal ao sobrado ou pavimento; podendo distribuir-se sobre os modelos á vontade de quem os estudar, segundo os diversos fins das composições; vantagens por certo importantíssimas a similhante Estabelecimento. Além d'isto o Edificio tem capacidade para officinas necessarias para quanto é material do Museo nos dous lados do nascente e norte [...]. (Ribeiro $1836,8)$

São claros os propósitos de trabalho e de instrução que acompanham o projecto museal. Contudo, a escala arquitectónica e a ocupação de uma importante área do convento por outros estabelecimentos ${ }^{16}$ levantaria problemas: não apenas o espólio seria depositado no pouco espaço restante, como os próprios estudantes, que entendiam necessária a frequência do Museu, iriam, inevitavelmente, carecer de espaço para trabalhar, obrigados a instalar-se excessivamente perto das obras já de si ameaçadas pela humidade.

A pobreza do edifício indiciava outras fragilidades. Sem a encenação de grandeza que a arquitectura confere, as obras perdiam poder de sedução. A carência de uma leitura de magnificência como a do Louvre, do Prado, ou do Museu Britânico, colocava-se não só para o público geral, mas também para os artistas. Foi inevitável a comparação com a situação de trabalho dos profissionais das artes nestes estabelecimentos, no conforto das suas amplas e bem iluminadas galerias, como várias imagens coevas abundantemente testemunham. E assim o Museu Portuense viveria os seus primeiros momentos de desilusão.

\section{Um projecto centrado em pinturas e estampas?}

E, contudo, a proposta pedagógica não se perdia de vista. Também no que diz respeito à escolha de objectos artísticos recolhidos se espelhava a intenção didáctica de Baptista Ribeiro, obedecendo assim ao mote lançado por D. Pedro - muito provavelmente na 
sequência da memória descritiva que o próprio Lente lhe entregara no primeiro encontro. E aí se percebe como, pouco depois, o projecto, inicialmente centrado em pinturas e estampas, sofria alguns desvios com as recolhas de obras de natureza muito diversa.

$\mathrm{Na}$ verdade, para o acervo concorreriam ainda objectos recolhidos em Tibães e em Coimbra. De novo a voz crítica de Pedro Vitorino se ergueria para acusar uma recolha muito centrada na pintura.

Com o fim de reünir materiais para o museu em projecto, constituiu-se uma comissão, presidida por João Baptista Ribeiro, de cujos trabalhos preparatórios parece não ficou nenhum documento. A sua principal preocupação incidiu sôbre pinturas e raramente se fixou em objectos. A colheita dêstes foi mínima.

Do mosteiro de Santa Cruz de Coimbra ainda trouxeram uns esmaltes limosinos, vinte e seis placas magníficas de excepcional valor, e a suposta espada do nosso primeiro Rei. Mais nada!/"Esculturas - e tantas havia nos conventos extintos nem uma só se guardou./"De mobiliário, recolta nula, à parte as mesas de mármore da sacristia conventual de S. Domingos, do Pôrto./"Nos outros ramos, ourivesaria, tapeçaria, iluminura, etc., a mesma coisa. (Vitorino 1930, xiv-xv)

Esta crítica não tem, contudo, em conta a intenção original do Lente que, ao contrário do que já tem sido escrito (Gonçalves 1889), não foi estabelecer um projecto generalista, mas especializado.

O primeiro museu "público" de "arte" português, pensado e concebido como tal, com um programa específico, inovador a vários títulos, que, no entanto, sofreu vários reveses, foi sem dúvida o Museu Portuense, concebido por João Baptista Ribeiro.

\section{Abertura pública e múltiplos reveses}

Com uma primeira abertura pública a 28 de Julho de 1834 (Ribeiro 1836, 8), o Museu passaria ainda por inúmeros sobressaltos.

Com cerca de 200 painéis colocados na galeria e outros 200 por colocar, pelas 11 horas da manhã entravam as majestades no Museu, em visita oficial, dando a bênção régia ao estabelecimento, numa inauguração que antecederia em seis anos a sua abertura efectiva.

Além das pinturas e gravuras, podiam igualmente ser vistas «tres ricas mezas de marmore, e sobre uma d'ellas a famosa Espada do Sr. D. Affonso Henriques, declarada pelo Immortal Duque de Bragança propriedade do Museo Portuense» (Ribeiro 1836, 9). No gabinete ao lado encontravam-se 32 estampas. Fazia ainda parte do espólio um núcleo de outras estampas e livros (poetas clássicos, viagens, costumes, antiguidades e História de vários países) considerados de interesse artístico. «Tudo em edições acompanhadas de estampas, aonde os estudiosos podem analisar, comparar, conhecer, e meditar os diversos modos que os desenhadores e gravadores seguírão para caracterisar, desenvolver e expremir os assumptos que pretendêrão tratar» (Ribeiro 1836, 9).

Cedo, porém, o Museu passaria por contrariedades que colocariam em causa a sua sobrevivência. $\mathrm{O}$ afastamento de D. Pedro IV da cidade do Porto, e a sua morte em 1834, levariam a que o Museu ficasse "moribundo", paradas as obras e posta em risco a preservação das peças já aí depositadas. Seria necessário que Baptista Ribeiro (Ribeiro 1836, 22) pedisse a intervenção do Duque de Palmela (1781-1850), então muito próximo da rainha D. Maria II, para que o Museu recuperasse ânimo e os trabalhos prosseguissem. A 22 de Outubro de 1834, uma portaria da soberana ordenava a prossecução das obras, receando que o mau estado do telhado e a aproximação do Inverno comprometessem a 
integridade de quadros, gravuras e estuques da galeria (Ribeiro 1836, 22). Pouco ou nenhum efeito causaria tal gesto, pelo menos durante meses. Passar-se-ia mesmo o Inverno, e a 25 de Abril de 1835, Agostinho José Freire (1780-1836) assinava enfim uma resolução que colocava à disposição do Prefeito do Douro a quantia mensal de 600\$000, destinada à continuação das obras no Museu e na biblioteca. A 28 de Maio seguinte, nova portaria nomeava uma comissão fiscalizadora, composta por José da Costa Lobo, Provedor do Concelho do Porto, Diogo de Góias Lara de Andrade, primeiro bibliotecário da Biblioteca Pública, João Baptista Ribeiro e Joaquim da Costa Lima e Sampaio, arquitecto da cidade (Ribeiro 1836, 22).

D. Maria II não cessaria o seu interesse pelo Museu Portuense, mantendo-se pronta a apoiar o director do estabelecimento, nas ocasiões em que este sentia necessidade de lhe recorrer; situação que demonstra, por um lado, como a autoridade de João Baptista Ribeiro não era reconhecida nos sectores políticos da velha guarda miguelista; e, por outro, como o Museu era entendido (por parte desses antigos foragidos) como usurpador.

Exemplo da fragilidade da instituição face aos ex-proprietários das obras, bem como a outros que continuavam a tentar alienar património para o estrangeiro, e do requisitado e concedido apoio da soberana foi a ordem de aquisição de dois quadros, datada de 27 de Agosto de 1835. Semelhante decisão complicaria a vida do director, que chegaria a receber ameaças de morte. De facto, Baptista Ribeiro fora o autor da sugestão de compra, desejando aumentar o acervo do $\mathrm{Museu}^{17} \mathrm{e}$, simultaneamente, impedir a alienação de tais bens.

A ameaça de morte revela a existência de um mercado paralelo para as obras de arte portuguesas (ou existentes no país), que então e durante muitas décadas foram produto de negócios clandestinos, fruto da inexistência de inventário e do descaso ${ }^{18}$. A recolha de pinturas e de estampas de extintos conventos e casas sequestradas (pertencentes a rebeldes fugidos) deu também origem a vários problemas, com que o director do estabelecimento se havia de deparar.

A 28 de Setembro de 1835, Baptista Ribeiro convocou de novo o auxílio da rainha, dandolhe conta de que o juiz de direito do Bairro de Santo Ovídio o intimara a entregar todas as obras pertencentes ao rebelde J. Luís da Silva Souto e Freitas, ameaçando o director com o espectro do calabouço, caso não cumprisse a ordem. Baptista Ribeiro defendeu-se com o facto de ser apenas Lente da Academia da Marinha e Commercio e, ao tempo de tais depósitos, simplesmente director interino do Museu, sendo D. Pedro IV o verdadeiro responsável pelas expropriações (Ribeiro 1836, 33).

39 Não era apenas um medo pessoal que movia Baptista Ribeiro a escusar-se e a pedir ajuda superior, mas o temor de que, caso o mau exemplo pegasse, o Museu se desvanecesse em fumo. Como nota na sua carta para a soberana:

Supposto S.M.I. sobremaneira generoso para com os inimigos da Patria, pôde perdoar-lhes os males por elles causados durante os tempos calamitosos da Usurpação, chegando a Ordenar q. se levantassem os sequestros de seus bens, que justamente lhe havião sido feitos, em razão do seu procedimento politico, parece comtudo que nesta acção generosa se não deverião nunca compreender aquelles objectos, q. emquanto os seus bens estavam sequestrados, isto he, quando lhes não pertencião, mas sim á Nação, forão, em virtude de varias Portarias, doados pelo mesmo Augusto Senhor a esta heroica Cidade, em premio de seus relevantes serviços. 
Se estas razoens não fossem sufficientes . $^{\text {a }}$ que V.M. mandasse desde ja suster semelhante procedimento, bastaria a consideração do quanto interessão as Artes na conservação deste Estabelecimento, p. ${ }^{a}$ q. tendo em vista o bem estar geral se não attendesse a injustas reclamaçoens particulares. (...) Se o exemplo se abre, Augusta Senhora, V.M. verá em hum momento desorganisados esses Estabelecimentos creados pelo Augusto Pai de V.M.: apparecerão immensas reclamações e justificações graciosas, exegindo aquillo q. por justissimos titulos foi dado para uso publico, quando o procedimento de seus antecedentes possuidores os havia tornado indignos de possuir como inimigos declarados da Patria e do Throno de V.M.

(Ribeiro 1836, 31-32)

0 receio do director não era injustificado. Não se podia permitir que um estabelecimento de utilidade pública, ainda para mais nascido como símbolo de gratidão para com o apoio político que a cidade concedera ao monarca, fosse desmantelado para servir precisamente aqueles que traíram a causa liberal ${ }^{19}$. Envolver a comunidade parecia ser a solução. Foi a essa questão que D. Maria II tentaria dar resposta, aprovando os estatutos da nova Associação Portuense dos Artistas de Pintura, Esculptura e Architectura - os Amigos das Artes -, permitindo as reuniões no Museu então também já conhecido por Atheneu D. Pedro, protegendo a associação e o estabelecimento, sempre com a ênfase de ser este o primeiro do género em Portugal (Ribeiro 1836, 23).

\section{Os amigos do Museu e a reiterada face pedagógica da instituição}

Semelhante associação, criada em 1835 , foi mais um passo importante no caminho para o ensino artístico, nomeadamente no que diz respeito às Academias de Belas-Artes. Em Junho desse ano, João Baptista Ribeiro, presidente da Associação, enviara a D. Maria a proposta de estatutos da instituição que devia funcionar nas instalações do Museu. Em Agosto esperando resposta, escreveu ao Ministro Rodrigo da Fonseca Magalhães (1787-1858), pedindo-lhe que tentasse obter a aprovação da soberana. A 2 de Novembro de 1835 , os estatutos foram por fim aprovados.

A Associação com este nome teria como objectivo congregar artistas e amadores, pretendendo «reunir debaixo de um centro os Artistas dispersos, e procurar fomentar a sua cooperação conjuncta, para mutuamente trabalharem por desenvolver o aperfeiçoamento destas Artes» ${ }^{20}$, de modo a contribuir para a «prosperidade Nacional, que necessariamente deriva das Artes» (Vitorino 1930, 56). Esta observação isolada poderá fazer pensar tratar-se do reconhecimento de mérito cultural da expressão estética. Porém, a continuação imediata do capítulo lança outra luz sobre o tema, esclarecendo que tais artes deveriam ser «comprehendidas no termo indústria»" propósito de viabilizar o tão necessário progresso industrial do país.

Porém, a sua função não se esgotaria aí. Composta por uma direç̧ão e uma assembleia geral de que faziam parte artistas e amadores que deviam propor a realização de quaisquer actos de interesse para o desenvolvimento artístico, cabia à direcção, eleita pela assembleia geral, a publicação de «obras elementares, para uso dos Estudantes de desenho de figura e paisagem» (Vitorino 1930, 56) ${ }^{22}$.

A contribuição de cada membro desta associação diferia segundo o seu estatuto de artista ou amador. Os primeiros deviam contribuir «com a sua industria», enquanto os últimos comparticipar com a entrega anual de «quatro mil e oitocentos reis, em metal» (Vitorino 
1930, 57). Tal como mais tarde sucederá com a Academia, todo o artista candidato a membro deveria apresentar a sua proposta, sujeita a votação, oferecendo, igualmente, uma obra sua para o fundo associativo. Instituiu-se além disso, a exposição anual, aberta a participações exteriores aos associados, numa tentativa de chamar público e diversificar interesses ${ }^{23}$.

A venda dos produtos expostos reverteria em $10 \%$ para a Associação que, a seu tempo, teria de publicitar a exposição e realizar o competente catálogo, no qual seria mencionada a comissão organizadora, para que o público soubesse em quem recaía a «responsabilidade da escolha» (Vitorino 1930, 58).

47 A juntar ao trabalho do Museu como instituição de defesa do património histórico nacional, também a Associação se esforçaria «por formar galerias das Personagens mais conspicuas d'esta Monarchia, em todos os seus tempos; e dos factos mais memoraveis da sua Historia passada e presente, e dos feitos do dia» (Vitorino 1930, 58). Este aspecto, aliado à nota do primeiro capítulo, onde se lia que os produtos da associação não deveriam vituperar politicamente nem o Governo, nem as autoridades governativas, mostra bem a face política deste esboço de escola de gosto, muito orientada para a História.

Aprovada a sua instalação no Atheneu D. Pedro, nesse mesmo dia 2 de Novembro de 1835, a Associação ver-se-ia instalada ainda no correr do mês. No discurso de apresentação, Baptista Ribeiro exultava, enfatizando o despontar da «risonha aurora das nossas suspiradas venturas» (Vitorino 1930, 59), e afirmando já ser «facil o affiançar aos Portuguezes que está perto o tempo da sua dezejada emancipação nas Bellas Artes» (Vitorino 1930, 59), acreditando na paz como benéfico terreno para o florescimento das artes, como já se vira noutros países. Baptista Ribeiro apresentava o exemplo de Inglaterra, e do papel protector de Jorge IV, comparando o gesto da soberana ao do monarca inglês.

49 Na construção deste país novo, o papel dos artistas não era de somenos. Eles exerceriam uma incontornável pedagogia, captando a história pátria em imagens, pretendendo-se que até crianças e camponeses a compreendessem na clareza dos traços, nas cores amigas com que se pintariam os nobres e justos, e na negrura convenientemente emprestada no registo do vício.

50 Tais venturas seriam, contudo, efémeras. A Associação teria vida curta. Pedro Vitorino, apontando a sua ausência no Diccionario Popular, de Pinheiro Chagas, onde se menciona simplesmente uma congénere criada em Lisboa, no mesmo ano de 1835, a Sociedade dos Amigos das Letras, dá-a como moribunda poucos meses depois. Mas a sua função tinha sido cumprida. Porque, entretanto, haviam sido criadas as Academias de Belas-Artes.

\section{Considerações finais}

51 O Museu Portuense mostra-se, assim, sem margem para dúvidas, como mais que o primeiro museu público de arte do país. Embrião das Academias de Belas-Artes, criou no seu seio a primeira associação de artistas com intuitos pedagógicos.

52 Até à sua efectiva abertura, ainda havia de se debater com inúmeros entraves. No termo do relatório, datado de 1 de Janeiro de 1836, Baptista Ribeiro dava conta de que, nos últimos dois anos, apesar das muitas dificuldades, o Museu despertara o interesse do público que o enriquecia de doações (de que uma das mais simbólicas fora a da Duquesa 
de Bragança, ofertando o chapéu emplumado com que o pai saudara as praias do Mindelo, e o óculo de que se servira nas campanhas).

Com objectos tão diversos, que iam de trabalhos artísticos a focas embalsamadas, vê-se claramente que, para o público, mesmo para o mais informado, o estabelecimento ainda era concebido como gabinete de curiosidades, programa bastante distante das intenções do seu director e organizador. Contudo, apesar dessa falta de entendimento do projecto original, das incapacidades, das dúvidas e dos adiamentos na abertura, o Museu Portuense logrou alcançar um primeiro efeito público importante: o do aumento das inscrições na Aula do Desenho, com a frequência de pessoas de todas as idades e situações, obrigando mesmo à suspensão da admissão por falta de lugares, no último par de anos lectivos. E não é de mais sublinhar: a curiosidade e a vontade de aprender subsistiam, apesar da incompletude dos trabalhos do Museu, da falta de meios financeiros e consequentes adiamentos das necessárias obras de adaptação. Com efeito, quase três anos depois da sua instalação, trabalhando gratuitamente o seu incansável director e demais pessoal, mantinham-se fechadas as portas.

O estabelecimento acabaria por abrir apenas quatro anos mais tarde, na conclusão das obras da galeria e da entrada do edifício. Eram três da tarde do dia 29 de Junho de 1840 . A partir de então, estipulado um horário de abertura sistemática que incluía domingos e feriados (Soares 1996, 86), ficava patente ao público o tão adiado Museu. E, acima de tudo, ficavam lançadas as sementes pedagógicas com que Baptista Ribeiro tanto sonhara.

\section{BIBLIOGRAFIA}

Almeida, António Manuel Passos. 2006. “Contributos ao Estudo da Museologia Portuense no Século XIX: O Museu do Coleccionador João Allen e o Museu Municipal do Porto." Revista da Faculdade de Letras: Ciências e Técnicas do Património I Série, vol. V-VI, 31-55.

Basto, Artur de Magalhães. 1932. O Pôrto do Romantismo. Coimbra: Imprensa da Universidade.

Brigola, João Carlos Pires. 2000. “Colecções, Gabinetes e Museus em Portugal no Séc. XVIII.” Tese de Doutoramento em História, Universidade de Évora.

Ferreira, Emília. 2001. “História dos Museus Públicos de Arte no Portugal de Oitocentos: 1833-1884." Dissertação de Mestrado em História da Arte, Universidade Nova de Lisboa.

Gonçalves, Amândio. 1889. O Museu Municipal do Pôrto o seu Estado Presente e o Seu Futuro. Relatório Apresentado ao Illustrissimo Senhor Luiz Ignacio Woodhouse Presidente da Commissão Encarregada de Estudar a Reorganização do Museu, pela Sub-Commissão, Encarregada das Secções de Bellas-artes, Archeologia e Numismática. Porto: Typ. A. J. da Silva Teixeira.

Machado, José Alberto Gomes. 1987. Um Coleccionador Português do Século das Luzes: D. Frei Manuel do Cenáculo Vilas-Boas, Arcebispo de Évora. Évora: Ciência e Vida.

Monnier, Gérard. 1995. L'Art et ses Institutions en France: De la Révolution à nos Jours. Paris: Gallimard. 
Owen, Hugh. 1915. O Cerco do Porto Contado por uma Testemunha: O Coronel Owen. Prefácio e Notas de Raul Brandão. [Lisboa]: Renascença Portuguesa.

Raczynski, Athanasius. 1846. Les Arts en Portugal: Lettres Addressées à la Société Artistique et Scientifique de Berlin, et Accompagnées de Documents. Paris: Jules Renouard.

Ribeiro, João Baptista. 1836. Exposição Historica da Creação do Museu Portuense, com Documentos Officiaes para Servir á Historia das Bellas Artes em Portugal, e á do Cêrco do Porto. Porto: [s.n.].

Santos, Paula Mesquita. 1995. "Museu Nacional de Soares dos Reis: Um Contributo para a História da Museologia Portuguesa." Museu, IV série: 3.

Soares, Elisa. 1996. "Pintura Portuguesa dos Séculos XIX e XX no Museu Nacional de Soares dos Reis: Constituição de uma Colecção." In Catálogo do Museu Nacional de Soares dos Reis. Museu Nacional Soares dos Reis: Pintura Portuguesa 1850-1950, 15-19. Porto: Ministério da Cultura.

Vitorino, Pedro. 1930. Os Museus de Arte do Pôrto (Notas Históricas). Coimbra: Imprensa da Universidade.

\section{NOTAS}

1. A autora escreve de acordo com a antiga ortografia.

2. Sublinho a questão de se tratar do primeiro museu "público" de "arte", visto já haver experiências museológicas prévias, em especial no domínio das ciências (ver, a propósito, Brigola 2000) e também experiências museológicas artísticas privadas, nomeadamente os museus de Tibães e o Museu do Cenáculo, em Évora (Ferreira 2001). Com efeito, embora organizados antes, não tiveram na sua origem propósitos públicos nem um plano pedagógico claramente definido como aconteceu com o Museu Portuense. Sobre este assunto ver também Almeida (2006-2007).

3. Em França, a mudança política no seio da qual nasceram os muitos museus públicos fora mais radical, como se sabe, abolindo até a monarquia e toda uma classe aristocrática satélite. Como afirmou Gérard Monnier, a revolução alterou a organização tradicional das artes. Com ela, nascem não apenas instituições e práticas artísticas novas, como também se vê modificada a relação do artista com o público. A época revolucionária, fazendo desaparecer uma clientela aristocrática, e questionando a legitimação da instituição monárquica, pôs também em xeque a própria arte e a sua função social numa sociedade cuja organização era já necessariamente outra. Coloca-se então a responsabilidade do Estado no desenvolvimento artístico (Monnier 1995, 19-20). Também entre nós, o Estado nascente, liberal (monárquico) aplicou-se a colocar a função social da arte como fulcro da sua acção política, assumindo responsabilidades, sublinhando a importância que o liberalismo reconhecia na educação como meio privilegiado para o progresso das nações.

4. O historiador portuense Artur de Magalhães Basto confirma esta visão (Basto 1932, 96).

5. Nascido em 1790, em Vila Real, morre em 1868, no Porto. Inicia formação artística em 1803, na Aula de Debuxo e Desenho da Real Companhia de Agricultura de Vinhas do Alto Douro, nesse mesmo ano integrada, tal como a Aula Náutica, na recém-criada Academia Real de Marinha e Comércio. Estudou com José Teixeira Barreto, Raimundo Joaquim da Costa e Domingos António de Sequeira. Admirador de Winckelmann, Mengs e dos pintores Poussin e Rafael, dedicou-se em especial ao retrato, inspirado no classicismo. Pintor real e professor desde 1811. Durante o cerco do Porto alistou-se como soldado. D. Pedro IV, porém, preferiu vê-lo entregue às artes, confiando-lhe a organização do Museu Portuense, de que foi director até 1836, data em que passou à direcção da Academia de Comércio e Marinha. Com a reestruturação do ensino artístico - criação das Academias de Belas-Artes de Lisboa e do Porto -, foi nomeado professor de desenho 
histórico nesta última; porém, acabaria por optar pela direcção da Academia Politécnica do Porto, onde leccionou até 1866. Foi também Comendador da Ordem da Conceição de Vila Viçosa, em 1824, Cavaleiro da Ordem de Cristo, em 1837, e Conselheiro de Estado, em 1853 (cf. Soares 1996, 26-29).

6. O saque terá sido geral, durante o cerco do Porto, indo dos víveres aos bens patrimoniais (Owen 1915, 205-206).

7. De notar que estas academias não são ainda as de Belas-Artes, mas as Aulas de Desenho da Academia de Comércio e Marinha do Porto.

8. No ponto 7 lê-se ainda: «O Publico terá entrada ás segundas e quintas feiras desde o primeiro d'Outubro até ao fim de Março da uma até ás quatro horas da tarde, e desde o primeiro de Março até o ultimo de Junho das tres ás seis. Os estudiosos serão admitidos nas terças, quartas, sextas e sabbados: desde Outubro até 31 de Março entrarão ás duas e sairáõ ás cinco da tarde, e desde Março até Junho ás tres e ás sete» (Ribeiro 1836, 17).

9. Algo que não é explicitado.

10. «(...) então será desterrado d'entre os artistas Portuguezes, o pessimo costume de trabalharem sobre principios puramente tradicionaes, por isso que lhes é vedado o conhecimento da verdade, isto é, o estudo do nú» (Ribeiro 1836, 16).

11. O Museu de Genebra a que se refere Baptista Ribeiro só poderá ser o Museu Rath, aí criado em 1826. O primeiro museu de Arte da Suíça foi criado com um claro projecto patrimonial e pedagógico. Para mais informações, ver http://institutions.ville-geneve.ch/fr/mah/lieuxdexposition/musee-rath/.

12. Não especifica, contudo, de que escolas se tratava (Ribeiro 1836, 18).

13. Não existe nenhum tipo de esclarecimento sobre quais poderiam ser esses artistas; apenas a ressalva de que os seus trabalhos deveriam ser moralmente decentes.

14. Trata-se da Academia de Marinha e Comércio.

15. A «área escolhida situava-se na zona oriental da urbe, nas proximidades do aprazível Passeio das Fontaínhas - alameda bem situada sobre a margem direita do Rio Douro cuja construção remonta ao tempo do corregedor Francisco de Almada e Mendonça - e dos teatros da cidade, e por isso seria muito frequentada pelo público, principalmente nas noites de Verão» (Santos 1995, 42). Pormenor curioso este, sobretudo se pensarmos que o Museu não tinha horário nocturno (Ribeiro 1836, 17).

16. A Biblioteca e a Academia Portuense de Belas-Artes partilharam o edifício a partir de 1836 .

17. «Senhora. V.M.F. Dignou-se visitar o Museo Portuense: esta honra so de per si ja he bastante para se poder asseverar que elle será lembrado a V.M.F.: as Ordens Generosas que V.M.F. Mandou expedir á Recebedoria do Douro para esta pôr á disposição do Prefeito do Douro $600 \$ 000$ mensaes até que o Museo e Biblioteca estejam prontos - he por certo hua Resolução digna da Filha do Augusto Fundador do Museo Portuense; e deixa antever que V.M.F. Se dignará continuar a proteger o Museo: agora tem elle ocasião de ser enriquecido com a posse de dous quadros excellentes, representando hum - Aves mortas grupadas, e pintadas magistralmente - o outro - he o feliz resultado do genio de quem ousou representar hua ave de rapina fendendo os ares e levando empolgado o filho de hua galinha que esprime, bem como hum galo e hum pavão, o mais energico interesse por seus filhos: - patenteia-se de hua maneira esplendida a grande abundancia de vida de todas as aves que testemunhão o facto, exprimido de modo que nada deixa a desejar. / "«Estes quadros estão á venda nesta cidade em Casa de Raimundo José da Costa, e nas vistas de varios Inglezes amadores que tratão de os comprar: forão vistos pelo Prefeito desta Provincia e outras pessoas que os admirão, e entendo que valem cem moedas, comprando-se barato, mas he de crer que os vendão por menos. / "«Seria digno de V.M.F. mandar compra-los para o Museo Portuense, a fim de serem ali vistos e estudados pelos Artistas Nacionaes, evitandose deste modo que sahião para fóra destes Reinos. Deus Guarde a preciosa vida de V.M.F. por muitos e dilatados annos. Porto 19 de Julho de 1835. João Baptista Ribeiro." Cito, ainda, o outro 
documento enviado pelo director do Museu ao prefeito do Douro, com os mesmos fins: "«Ill.mo e Ex.mo S.r O interesse Publico obriga-me a pôr na presença de V. Ex.a a representação incluza á cerca de dous quadros que se achão á venda nesta Cid.e em casa de Raimundo José da Costa, a fim de que V. Ex.a se sirva eleva-la á Presença de S.M.F. para evitar que aquellas produções d'Arte passem a ser possuidas por mãons estrangeiras: o patriotismo de V. Ex.a affiança desde já hum feliz resultado a esta acquisição em favor das Bellas Artes. Deus Guarde a V. Ex.a Porto 19 de Julho de 1835. Ill.mo e Ex.mo Sr. Visconde de S. Gil de Perre, Prefeito do Douro. João Baptista Ribeiro» (Vitorino 1930, 29-30). De notar que o director do museu não apenas detinha uma clara consciência histórica, como se nota nos propósitos que o levaram a compilar toda a documentação trocada aquando da organização do Museu, como também tinha uma muito clara noção de património artístico, que o levou a propor a criação do estabelecimento, mantendo uma permanente atenção à venda de obras de arte que tentará, a todo o custo, não deixar sair do país.

18. E assim continuaria durante décadas, como se pode constatar pelos testemunhos de Luciano Cordeiro, Joaquim de Vasconcelos e Ramalho Ortigão, entre outros.

19. Um caso com algumas semelhanças a este ocorrera em 1777, com Frei Manuel do Cenáculo. Pina Manique, em carta de 19 Setembro, dando-lhe a conhecer uma decisão de «D. Maria I de fazer restituir ao marquês de Alorna as jóias móveis e obras de arte "desencaminhadas" por altura da sua prisão, no reinado anterior, à ordem de Pombal. Após diversas investigações, apurou o Intendente estarem na posse de Cenáculo grande parte das pinturas e manuscritos do marquês» (Machado 1987, 34). Os quadros, nesse caso, seriam devolvidos.

20. Estatutos da Associação Portuense, dos Artistas de Pintura, Esculptura, e Architectura, denominada: Dos Amigos das Artes (Vitorino 1930, 56).

21. Relembremos que as artes industriais ou decorativas eram uma e a mesma coisa (Vitorino 1930, 56).

22. Não é certo se tais publicações tiveram concretização.

23. «Haverá todos os annos uma Exposição dos productos da Associação e de outros, que a Associação por uma Commissão de trez Membros julgue dignos de entrarem na sua exposição» (Vitorino 1930, 57).

\section{RESUMOS}

Porto, 1833. Recompensando esforços e derramamento de sangue, D. Pedro IV, ainda em batalha, afadigava-se entre a distribuição generosa de títulos nobiliárquicos e cumplicidades com os espíritos mais propensos ao enaltecimento do nascente poder liberal. Foi neste quadro que surgiu, em pleno cerco à cidade do Porto, a ideia da "medalha simbólica" à população, através da criação de uma instituição destinada a marcar tal esforço. Nasceu assim o primeiro museu "público" de "arte" português, o Museu Portuense, projecto de claro pendor pedagógico. Com a sua criação não se pretendia responder a todas as necessidades nacionais, mas colmatar falhas como a falência de espaços onde estudiosos e amadores de arte pudessem ilustrar-se. Foi esse o sonho do seu organizador e primeiro director, João Baptista Ribeiro, nome fundador da museologia portuguesa.

Porto, 1833. Rewarding personal efforts and spilling of blood, king Pedro IV - while still on the battlefield - rewarded his followers, and all those capable of enhancing the liberal power, with nobility titles. All this happened while he was under siege, stationed in the city of Porto. It was 
then that the idea of granting a symbolic medal to the population, through the creation of an art museum, crossed his mind. Such a place would glorify the new institutional power. In this way was born the first public art museum in Portugal, the Museu Portuense, developed with a clear pedagogical programme. The establishment was not intended to answer all of the nation's artistic and cultural needs, but it certainly helped, creating a place where scholars and art lovers could cultivate themselves. Such was the dream of its organizer and first director, João Baptista Ribeiro, a name to remember in Portuguese museology.

\section{ÍNDICE}

Palavras-chave: Museu Portuense, João Baptista Ribeiro, museu de arte, história do museu, história da museologia

Keywords: art museum, museum history, museology history

\section{AUTOR}

\section{EMÍLIA FERREIRA}

Licenciada em Filosofia pela Faculdade de Letras da Universidade de Lisboa; mestre em História da Arte pela Faculdade de Ciências Sociais e Humanas da Universidade Nova de Lisboa com uma dissertação subordinada ao tema História dos Museus Públicos de Arte no Portugal de Oitocentos: 18331884 (2001) e doutora em História da Arte com a tese Lisboa em Festa: a Exposição Retrospectiva de Arte Ornamental Portuguesa e Espanhola, 1882, Antecedentes e Materialização (2010), na mesma Universidade.

Instituto de História da Arte, Faculdade de Ciências Sociais e Humanidades da Universidade Nova de Lisboa, Av. de Berna, 26-C, 1069-061 Lisboa, Portugal, meofster@gmail.com 